University of Windsor

Scholarship at UWindsor

2012

\title{
Influence of participation, facilitator styles, and metacognitive reflection on knowledge building in online university courses
}

\author{
S. Cacciamani \\ D. Cesareni \\ F. Martini \\ T. Ferrini \\ N. Fujita \\ University of Windsor, nfujita@uwindsor.ca
}

Follow this and additional works at: https://scholar.uwindsor.ca/open-learningpub

Part of the Curriculum and Instruction Commons, Higher Education Commons, and the Online and Distance Education Commons

\section{Recommended Citation}

Cacciamani, S.; Cesareni, D.; Martini, F.; Ferrini, T.; and Fujita, N.. (2012). Influence of participation, facilitator styles, and metacognitive reflection on knowledge building in online university courses. Computers \& Education, 58 (3), 874-884.

https://scholar.uwindsor.ca/open-learningpub/6

This Article is brought to you for free and open access by the Office of Open Learning at Scholarship at UWindsor. It has been accepted for inclusion in Office of Open Learning Publications by an authorized administrator of Scholarship at UWindsor. For more information, please contact scholarship@uwindsor.ca. 


\section{Accepted Manuscript 29 October 2011 \\ Please cite as}

Cacciamani, C., Cesareni, D., Martini, F., Ferrini, T., \& Fujita, N. (2012) Influence of participation, tutorship styles, and metacognitive reflection and knowledge building in online university courses. Computers \& Education, 58 (2012), 874-884. doi: 10.1016/j.physletb.2003.10.071

\section{Influence of participation, tutorship styles, and metacognitive reflection and knowledge building in online university courses}

Stefano Cacciamani, University of Valle d'Aosta, Strada Cappuccini 2/A, 11100 Aosta, Italy. $\underline{\text { s.cacciamani@univda.it }}$

Donatella Cesareni, University of Rome "Sapienza", Via Dei Marsi 78, 00185 Roma, Italy. donatella.cesareni@uniroma1.it

Francesca Martini, University of Rome "Sapienza", Via Dei Marsi 78, 00185 Roma, Italy. fmartini.lumiere@gmail.com

Tiziana Ferrini, "Regina Maria Adelaide" High School Institute Via Torino 55, 11100 Aosta, Italy. is-madelaide@regione.vda.it

Nobuko Fujita, Copenhagen Business School, Howitzvej 60, 2nd floor, DK-2000, Frederiksberg, Denmark. fujita@cbs.dk

Corresponding author: Stefano Cacciamani, University of Valle d'Aosta, mailing address: Strada Cappuccini 2/A, 11100 Aosta, Italy 
email: $\underline{\text { s.cacciamani@ univda.it, }}$

phone number: +39-0165-306711

fax number: +39-0165-32835

\begin{abstract}
The purpose of this paper is to analyze how different levels of participation, tutorship styles, and metacognitive reflection in an online course can influence the group's knowledge building. 131 undergraduate students in Psychology and 59 students in the Educational Sciences and Primary Education Sciences participated in the study. Results show that a central level of participation is associated with a higher level of epistemic agency required for Knowledge Building. A supportive tutorship style and opportunities for metacognitive reflection on their own participation strategies are also related to the students' advanced epistemic agency. Implications of these results for research and instructional design of online courses are discussed.
\end{abstract}

Keywords: computer-mediated communication; cooperative/collaborative learning; pedagogical issues; teaching/learning strategies; post-secondary education 


\section{Introduction}

More than 1.9 million American university students have taken advantage of distance learning opportunities through the Internet. Such a number would have increased to 3.9 million in 2007, about $20 \%$ of all university students (Allen \& Seaman, 2008). In addition more than $80 \%$ of US colleges offer at least a course that is either completely online or blended (Allen \& Seaman, 2004). Other authors report similar data for postsecondary education in the US and Canada (Lewis, Levin \& Green, 1999; LaGrange \& Foulkes, 2004). From an economic perspective, in Europe the investment in e-learning in 2002 exceeded six billion dollars and it almost quadrupled in 2006, making it easy to forecast future growth (Bonaiuti, 2006). E-learning is therefore beginning to proliferate as an educational method in the academic field, and has become the focus of much research.

Our experience indicates, however, that there is still some resistance to embracing online teaching methods using discussion forums: more time is needed to teach online in comparison to face-to-face lessons, a higher teacher commitment is necessary when planning the courses, and teachers frequently face technical difficulties. In some contexts the limited use of this teaching method can be seen in its irreconcilability with many traditional teaching methods. Understanding and answering teachers' worries is fundamental to further adoption of online teaching. In addition, in spite of the positive results highlighted by literature, a higher percentage of drop-out rates is detected in online courses in comparison to face-to-face courses (Martinez, 2003). The nascent field of academic analytics (Campbell, De Blois, \& Oblinger, 2007) and learning analytics (Siemens, 2010), for example, is particularly interested in reducing attrition and in identifying the conditions facilitating meaningful learning for elearners and thus ensuring the educational effectiveness of online courses.

Some factors can contribute to the educational success of online activity: teachers' motivation and satisfaction (Shea et al., 2005), students' levels of participation, online tutor 
support and the arrangement of spaces for metacognitive reflection on the online training experience (Cesareni, Albanese, Cacciamani, Castelli, De Marco, Fiorilli et al., 2008).

A study by Shea, Pickett and Sau Li (2005) of the SUNY Learning Network (SLN), analyzes the satisfaction of teachers from different faculties towards their online teaching experiences. The results suggest that the teachers are satisfied by the online teaching experiences, state that their students have learnt much, and would like to teach online courses again. In addition, this research indicates that the quality of interaction, the technical support, the positive learning experience fulfilled while teaching in an online course, and the specific area of the subject are factors that meaningfully weigh on the teacher's satisfaction with online teaching.

The importance of participation in an educational context is underlined by Lave and Wenger (1991) who reconceptualizes learning in terms of social practice realized within a community. The process called legitimate peripheral participation (LPP) is fundamental; it describes the progressive participation of less skilled members in community practices, through which these members gain the necessary expertise to reach a full participation. This happens through a gradual shift of the individual from the periphery to the center in the participation in the community's activities. Research into online learning defines participation as involving different forms and using different analysis units (Hrastinski, 2008). Participation may be detected from numerical indicators such as the number of accesses to the platform, the number of written messages; content analysis of the quality of the messages; the relationship between the reading and writing; and the perception the students have of the activity through interviews, questionnaires and reflective learner reports. The students' participation in the activity in terms of quantity of messages posted in the forum seems to be influenced by the quality of infrastructures put at the students' disposal (Cesareni \& Martini, 2005). High numbers of student contributions is not always correlated to their learning 
performance. In fact, Hwang and Arbaught (2009) found that those who write fewer messages, but participate in the discussion regarding a wider number of topics, achieve better results in the final knowledge test in comparison to those who write more but are limited to only one topic of discussion.

A further element that can affect the effectiveness of an online course is represented by the role of the tutor. A survey of the literature reveals a variety of studies about the functions, tasks, and skills required by the tutor. Berge and Collins (1996) identify the roles of the tutor as Instructor, Moderator, and Facilitator, distinguishing at least four categories that influence the effectiveness of online courses. Similarly, Luciani (2007) identifies pedagogical, social, organizational-procedural, and technical skills that the tutor requires. Calvani and Rotta (2000) draw on Berge and Collins' profiles of the tutor, and define an online tutor as instructor e-tutor, facilitator e-tutor, and moderator/ supportive e-tutor. Finally, Rotta (2002) writes that the instructor role is more oriented towards work on content that promotes the participants' individual learning; facilitator role is towards the management of one-to-one communication by e-mail students and through open chat discussions in small groups; and the moderator role is oriented towards different forms of scaffolding of the community's cooperative activity that is created during the online course.

In addition to research outlining the e-tutor's function (Tallent-Runnels et al., 2006), other studies have focused on the tutor's style of interaction and on information management. These dimensions are useful in fostering online participation and the cognitive presence of the students (Edwards \& Fintan, 2001; Garrison \& Cleveland-Innes, 2005; Kim \& Gil, 2007; Koh et al., 2007; Moshinskie, 2002). They are also helpful in studying how to reduce the risk of edropouts (Booker \& Rebman, 2005; Moshinskie, 2002). Beyond the several facets the tutor can provide, being able to define a style of interaction to favor cooperation with and among the students seems essential, starting from a fundamental premise: a moderated online 
community is preferable in comparison with a non-moderated one (Wise, Hamman, \& Thorson, 2006). From a review of the research carried out in this field (Wise et al., 2006; Mazzoni, 2005; Zhu, 2007; Cesareni et al., 2008), it appears that tutor-student interactions have been examined from a quantitative approach. The qualitative aspects of tutorship seem decidedly less explored, for example, the possibility of a tutor to use a more "supportive" style rather than an "oppositional" one. By "supportive," we define a tutorship style aimed at encouraging the students to express themselves in the forum; whereas by "oppositional," we refer to a tutorship style oriented to stimulate a socio-cognitive conflict among the participants, to favor the externalization of arguments that are increasingly articulated during the discursive process by the students.

Another factor which can play an important role in favoring the training effectiveness of online courses is represented by the students' metacognitive skills, in particular the selfregulative ones (Choi, Land \& Turgeon, 2005; Sánchez-Alonso \& Vovides, 2007). The selfregulated student is able to plan strategies and continually adapt them to reach a goal (Zimmerman, 2002). In this perspective, self-regulated learning involves the active role of the individual in planning, monitoring and evaluating the action (Zimmerman, 2000; Pellerey, 2003). In an e-learning activity the students are involved in a new metacognitive challenge that requires a change in strategy to be able to orientate oneself among the plurality of perspectives and information (Mayer, 2003; Narciss, Proske \& Koerndle, 2007). Development of metacognitive expertise, conceptualized as consciousness of the strategies entailed in the different tasks and more suitable for the different goals, is favored by collaborative interaction among peers (Palincsar \& Brown, 1984; Scardamalia et al., 1989). The virtual environment organized through discussion forums, where e-learners meet and discuss, exchange and build knowledge, represents a tool which enables the coming to light of socio-cognitive conflicts, requiring metacognitive adjustment skills of those conflicts (Berge 1997; Chan, Burtis \& 
Bereiter, 1997; Scardamalia \& Bereiter, 2006). In these learning environments the participants can consider some different points of view on the same problem, justify and discuss their ideas, negotiate in order to reach common understanding, as well as have the space for metacognitive reflection to think about the used strategies.

In this paper, we examine how levels of participation, tutorship, and metacognitive reflection influence online course discussions from the perspective of Knowledge Building, an inquiry learning pedagogy focused on theory building. Many authors (Scardamalia \& Bereiter, 1992; Scardamalia \& Bereiter, 1994; Muukkonen Hakkarainen \& Lakkala, 1999; Cesareni, Ligorio \& Pontecorvo, 2001; Cacciamani, 2001; Cesareni \& Martini, 2005) actually underline that the pedagogical use of web-forums in education enables a most effective and productive learning only if oriented towards collaborative knowledge building: the students work together to elaborate ideas, to compare and solve common problems (Lakkala, Rahikainen \& Hakkarainen, 2001). In order to study the collaborative knowledge building processes, some models and frameworks try to describe and explain how these processes take place. This is the case with the Progressive Inquiry Model (Muukkonen et al., 1999) and the Knowledge Building Community pedagogy (Scardamalia, 2002).

The Progressive Inquiry Model, developed by Hakkarainen and his colleagues, is based on theories of Knowledge Building (Scardamalia \& Bereiter, 1994), the interrogative model of scientific inquiry (e.g., Hakkarainen \& Sintonen, 2002), and concepts of distributed expertise in a community of learners (Brown \& Campione, 1994).

Knowledge Building theory is defined by 12 principles (Scardamalia, 2002) describing a system of socio-cognitive and technological dynamics that allow a group to create new knowledge around a problem of common interest for a community. Among these principles is "Epistemic Agency," in which 
Participants set forth their ideas and negotiate a fit between personal ideas and ideas of others, using contrasts to spark and sustain knowledge advancement rather than depending on others to chart that course for them. They deal with problems of goals, motivation, evaluation, and long-range planning that are normally left to teachers or managers (Scardamalia, 2002, p.10).

Epistemic Agency represents a strong indicator for Knowledge Building activity of the students.

The purpose of this research is to expand on the data corpus of a previous explorative research (Cesareni et al., 2008) and analyze how different levels of participation and ways of organizing an online higher education course can influence its success in terms of the group's Knowledge Building, using the Epistemic Agency principle as an indicator of engagement.

A first hypothesis concerns the possible existing relationship between the students' active participation in discussion and the tendency they have towards Knowledge Building. We hypothesize that students who participate in the activity in a central way, i.e., who write a large number of messages, are also particularly active contributors in building new knowledge. They do not limit themselves to searching for or commenting upon "pre-packed" knowledge, but turn their attention to the explore problems and to evaluate both the content of discussion and strategies for self-regulated learning in discussion forums. A second hypothesis considers the possibility that tutors' different interactional styles can influence the students' knowledge building process. Finally, a third hypothesis posits that specific metacognitive reflection strategies enhance the Knowledge Building process of the group.

\section{Material and methods}

\subsection{Participants}


A total of 131 university students attending the faculty of Psychology at "Sapienza" University of Rome (13 males, 59 females) and 59 attending Educational Sciences and Primary Education Sciences at the University of Valle D'Aosta (9 males, 50 females) took part in the learning activity. The activity was led by two teachers (one in Rome and one in Aosta) and by four tutors (two in Rome, two in Aosta).

All the students were involved in a blended learning activity (online and in the classroom) aimed at collaborative Knowledge Building on topics aligned with course or module requirements. The students from Rome were enrolled in the third-year course in Psychology and the activity was inserted in the module, Educational Technologies. The students from Aosta were students enrolled in either the first year or second year a in Educational Sciences program, and the discussion activity was inserted within the online Educational Psychology course. The students voluntarily chose to take part in the blended activity within their courses.

\subsection{Setting}

The learning activity was organized in both the classroom and online settings. Face-toface meetings were were held onsite on campus to discuss the contents of the course and ways in which to use the various virtual environments. The online discussion was oriented towards analyzing particular topics highlighted in the courses, in different ways between the two universities. At the University of Rome the discussion topics were identified by the students themselves, following an online brainstorming session: for instance, the use of the technologies in schools, the relationship between technologies and people with disabilities, and collaborative learning through technologies. The learning activity in Aosta was divided into modules and the discussion started from issues highlighted by the lecturer. Among these 
topics were, for example "study motivation", “collaborative learning”, and "observation in educational settings"

The students at both universities were divided into seven discussion groups: five in Rome and two in Aosta, varying numerically from 13 to 30 people depending on the needs of the course itself. Every student was registered in whichever online environment that was used (Knowledge Forum or Synergeia, described below) and placed randomly in one of the online discussion groups. Each group worked independently from the others and was followed by a tutor and by the teacher as a supervisor. The students had access to the platform both from the university and from home or from other places they had chosen.

\subsubsection{Online environments}

The two universities used two different online environments: Knowledge Forum and Synergeia, both built to support collaborative learning and inspired in particular by the Knowledge Building pedagogy (Scardamalia \& Bereiter, 2006).

Knowledge Forum (http://www.knowledgeforum.com) is an extention of CSILE (Computer Supported Intentional Learning Environment) software, an online environment specially designed to support Knowledge Building. It was created by the research group at the University of Toronto under the direction of Carl Bereiter and Marlene Scardamalia. In Knowledge Forum, students can contribute ideas represented as "notes" (written text to which graphs and images can be added). Students can also build-on or reference ideas in other notes to advance the state of the knowledge in the community or highlight some key words for inquiry in their own notes. In addition, Knowledge Forum allows students to connect notes in one "view" or virtual space to another through hyperlinks to overcome some barriers posed by the chronological sequence of notes.. To facilitate progress in discussion there are also some pre-defined linguistic structures, called "scaffolds" or labels of thinking types, which are used 
while composing a note . Knowledge Forum comes with two types of scaffolds, Theory Building and Opinion, but it is possible to customize scaffolds to support local needs.

Synergeia (http://bscl.fit.fraunhofer.de) is a web-based platform used experimentally within the European project ITCOLE (Innovative Technologies for COllaborative LEarning, supported by the European Community under the Information Society Technology RTD program). Synergeia was also designed to support collaborative knowledge building. It enables document sharing through easy uploading or downloading of various file formats, including texts or multimedia, and allows users to organize and comment upon them within a common work space. The knowledge building areas are discussion forums where teachers or students can contribute messages to start a discussion and/or respond to the others' contributions contributing to the collective building of meanings. In Synergeia the labels for thinking types are present as well. The student can attribute a thinking type label to the note to categorize its contents. These thinking types are based on the Progressive Inquiry model (Muukkonen, Hakkarainen \& Lakkala, 1999).

\subsection{Procedure}

The main goal of this research is, as we have already stated, to inquire as to how different levels of participation and different ways of course organization could influence the positive results of the course itself in terms of Knowledge Building.

The observed variable is therefore the Knowledge Building activity, using Scardamalia's (2002) notion of Epistemic Agency as an indicator of engagement. Epistemic Agency indicates the commitment by the students to improve ideas, negotiating an adjustment between their ideas and those of others, trying hard to realize a deep insight into the problems that are the core matter of the inquiry and to elaborate new knowledge. In the following section we describe how this variable is measured in the current study. 
Each online discussion group was randomly attributed to a different way of course management depending on the research variable taken into account. At the end of the course, the level of the students' participation in the activity was analyzed.

The independent variables are the participation level, the tutorship style and the presence or not of a metacognitive reflection activity.

\subsubsection{Level of participation}

The first variable refers to the level of participation of the students in the activity. The students were divided into three levels of participation according to the posted messages. Only the messages concerning the discussion topics were considered; messages of pure social interaction, technical requests about the use of tools and simple agreements and disagreements, without other content, were omitted. In keeping with the literature that considers the relationship among the participants as being relevant in defining online participation (Hrastinski, 2008), we have taken into account only the answer messages and build-on notes in existing discussions rather than new notes. Then we calculated for each student the number of build-on messages concerning the discussion topics posted. We focused our analysis on examining students below $30^{\text {th }}$ percentile, who we defined as having a low level of participation (or peripheral participation), and those exceeding $70^{\text {th }}$ percentile, who were defined as having a high level of participation (or central participation). Finally, we analyzed the content of the messages written by those students who had taken part in the learning activity with central participation or peripheral participation, as defined above. Focusing on this subset of data is based on the assumption that it will allow us to estimate better the effect of the other organization variables (tutorship style and metacognitive reflection) on Epistemic Agency, bearing in mind the heterogeneity of the students' participation level without having to broaden the content analysis to all the participants. 
The number of students that were included in this analysis were 67 (41 in Rome, 26 in Aosta). Among these 67, 31 students from Rome were considered for the "tutorship style" variable, and the other 36 (both in Rome and Aosta) for the "metacognitive reflection" variable. In each variable group (tutorship style and metacognitive reflection) half the students were central and half were peripheral.

\subsubsection{Tutorship style}

Two groups of students from the University of Rome took part in a forum where the tutor enacted a tutorship style defined as "oppositional". The goal of his contributions was to generate a cognitive conflict and to stimulate the argumentative abilities of the same students. Through his messages the tutor raised some doubts and questions on the introduced concepts (Why should the Internet be a synonym of danger and most of all of paedophilia? Why should it "deflect from the true pleasures in life"?); he either invited a further deepening of the discussion or asked for further explanation ("I think this discussion needs a more scientific setting: I don't think you have dwelled upon a first and fundamental definition of the term bullyism").

In two other groups from Rome, the tutor carried acted out a tutorship style defined as "supportive". The goal of his contributions was to support and raise the contents of the discussion and provide useful materials for the discussion itself. The supportive tutor took part then to encourage everyone's participation ("Rosaria, I was told by your teacher that you are a teacher... how about telling us something about your experience in using computers (and the Internet) at school?"), to offer theoretical contributions (Regarding the discussion on the writing activity, I would like to propose to you an extract of a discussion among elementary school children reflecting on writing with "pen and paper" and "using a computer") and to raise ideas expressed by some or underlining constructive contributions (“Excellent Giovanna, it can surely be useful for our knowledge building”). 


\subsubsection{Metacognitive reflection}

The third design variable used was the organization, within three courses at Rome and Aosta, of discussion spaces inviting a personal reflection of a metacognitive kind concerning Knowledge Building by the group and the strategies used. Towards the middle of the online discussion activity, students were invited to answer the following questions:

- Which two ideas do you judge to be the most interesting ones arising from the discussion in this module?

- Which work strategy have you used?

- Which strong points and which critical ones have shown this strategy?

The students discussed these questions in a shared space, proposing personal answers and critically commenting upon their colleagues' replies. At the end of the activity, three groups assigned to the "metacognitive reflection" then faced a final discussion, answering six questions concerning the activity they had carried out. The other two groups performed the activity without taking part in the metacognitive reflection, neither during the course nor afterwards.

In Tables 1, 2 and 3 below, a synthesis for each of the three variables is shown (participation level, tutorship style, metacognitive reflection,) as well as the number of students whose contributions were analyzed in the content.

[Insert Table 1 about here]

[Insert Table 2 about here]

[Insert Table 3 about here]

\subsection{Tools}


Epistemic Agency, a variable observed in this research, was operationalized as Basic Epistemic Agency and Advanced Epistemic Agency, through a content analysis coding scheme. The coding scheme was tested in previous inquiries with good interrater reliability among independent judges (Cacciamani \& Ferrini, 2007; Cesareni et al., 2008). Such a scheme distinguishes content coding categories divided into two levels: the first one is composed by sub-categories of the second one (Table 4).

[Insert Table 4 about here]

The first level sub-categories of the tool were built according to the "thinking types" or "scaffolds" in the online Knowledge Forum environment adapted from to a similar scheme developed by Cesareni and Martini (2005). These sub-categories aim to detect the different kinds of contributions that the participants in a Knowledge Building Community can carry out in a Knowledge Building activity. The second level categories, grouping the first level subcategories, have been defined in terms of activities, such as:

- Proposing information: including contributions like "Practical examples" and "Information drawn from reliable sources and data concerning experimentations";

- Elaborating information: including contributions like "Repetition of another community member's idea", "Synthesis of several ideas";

- Exploring: including contributions like "Inquiry questions or problems", "Hypothesis on contents";

- Evaluating: including contributions like "Comments" and "Metacognitive reflections".

The first two activities (Proposing and Elaborating information) were considered as indicators of "Basic Epistemic Agency," as expressing an answer attitude to the knowledge process fulfilled by others. For example, a student who answers a question posed by the 
teacher in the forum by posting information taken from the course manual or proposing an example drawn from his/her experience would be displaying Basic Epistemic Agency. The last two activities (Exploring and Evaluating) were considered as markers of "Advanced Epistemic Agency" more suitable to stimulate the Knowledge Building process. This is the case when a student, faced with the same question from the teacher, contributes to the group's Knowledge Building by formulating his/her own hypothesis, proposing a further question to deepen or critique the answers or metacognitive reflections on the work strategies.

The coding scheme was applied to "segments" of the messages in the forums, that is to say a unit of meaning, corresponding to a sentence identified through the punctuation used by the same authors of the messages themselves (full stop, semicolon, colons, suspension dots, exclamation and question marks). Some independent judges coded the segments from the discourse data from both Rome and Valle d'Aosta. An inter-rater agreement (Cohen's kappa) of 0.92 for Rome and 0.80 for Aosta, respectively, were achieved, which is considered in the literature as an acceptable level of agreement among the judges.

\section{Results}

As already stated, the blended activity involved seven discussion groups, five at the University "Sapienza" in Rome and two at the University of Valle d'Aosta. In total, 25 discussion spaces were opened on topics concerning the course. Five groups on the Education Technologies course in Rome chose, through online brainstorming, to discuss topics concerning the use of technologies in educational contexts (for example, the use of the Internet at school, the relationship between technologies and people with disabilities, collaborative learning through technologies). In Aosta the discussions started from problems raised by the lecturer in the sub-modules devoted to learning theories, motivation to study, 
collaborative learning and observation in educational contexts in an Educational Psychology course,

For our research, as made explicit in the method, we chose to analyze only the contributions of the most active students in the discussion ("central" in writing their contributions) and the ones who were less active ("peripheral" in writing their contributions). We thus focus our analysis on a subset of 67 students, 41 students at the University Sapienza in Rome and 26 students at the University of Valle d'Aosta.

[Insert Table 5 about here]

As shown in Table 5, in total 977 notes were written by the students, with an average of about 14 contributions per student. The notes on average contained 5.6 segments, showing a sufficient complexity in the message articulation.

[Insert Figure 1 about here]

Overall, content analysis of the notes (see Figure 1) highlights a prevalence of formulating hypothesis (37.5\%), followed by a good percentage of theoretical deepening $(21.6 \%)$ and practical examples $(16.5 \%)$. The syntheses of the discussed contents are virtually non-existent $(0.4 \%)$.

The students therefore propose many explanations of the discussed matters (hypothesis) and support their hypothesis referring both to the authors' theories (information) and quoting practical examples concerning their experience (practical examples).

Amalgamating the segments in the overarching categories defining the Epistemic Agency's levels (Basic or Advanced), we can notice that promisingly, the students are generally more oriented towards an Advanced Epistemic Agency (see Figure 2): they more often follow an explorative approach and evaluate problems and proposed solutions (Advanced Epistemic Agency, 56\%) rather than embracing an approach aimed at proposing and/or elaborating information (Basic Epistemic Agency, 44\%). 
[Insert Figure 2 about here]

First, let us consider the different levels of participation in the activity, dividing, as previously stated, the students into two groups following the number of written notes (central and peripheral participants) (Table 6).

\section{[Insert Table 6 about here]}

As shown in Table 6, both the students with peripheral participation and those with central participation tend to write contributions mainly at an Advanced Epistemic Agency level, but in a more emphasized way as far as the students defined as central are concerned. The difference between the two groups is statistically meaningful $\left(X^{2}(2, N=67)=5.88\right.$; $\mathrm{p}<$ .02). It seems therefore that a high participation in the activity is associated with a greater tendency to explore and evaluate the developed knowledge and the strategies used to elaborate it. These students are not then at the centre of the community only due to the high number of written notes, but also due to the active function they undertake in the building knowledge process.

The second variable taken into account in our research is the tutorship style (either supportive or oppositional) activated in four different discussion groups at the University “Sapienza" of Rome (Table 7).

\section{[Insert Table 7 about here]}

All the groups with both tutorship styles tend towards an Advanced Epistemic Agency, although in a higher way for the students who had a supportive tutorship style $\left(X^{2}(2\right.$, $N=31)=4.82 ; \mathrm{p}<.05)$. It seems therefore that supporting the discussion favoring everyone's participation, mirroring the interventions and underlining meaningful contributions, is a great help for the students to orientate themselves towards a discussion aimed at an active building of new meanings (Advanced Epistemic Agency). 
Let us consider now the relationship between the Epistemic Agency and the presence or not of metacognitive reflection spaces. Two groups of students from Aosta and one from Rome took part in the activity reflecting, during their course, upon the created knowledge and upon the strategies used to build it. Their discussions were compared to those of the students of the other two groups from Aosta who did not have this possibility.

\section{[Insert Table 8 about here]}

Table 8 highlights that the students who took part in the course with metacognitive reflection spaces tend towards an Advanced Epistemic Agency, while those who took part in the course without any metacognitive reflection tend towards a Basic Epistemic Agency $\left(X^{2}\right.$ $(2, N=36)=13.05, \mathrm{p}<.001)$.

\section{Discussion}

The goal of this study was to analyze the influence of different levels of participation, tutorship style, and metacognitive reflection on the students' Knowledge Building activity. First, the results show that a high level of participation (central participation) in the online discussion is associated more strongly with an Advanced Epistemic Agency than with a low level of participation (peripheral participation). Second, a tutorship style aimed at supporting participation (supportive style) seems to foster an Advanced Epistemic Agency more than a tutorship style aimed at activating a socio-cognitive conflict in the online discussion (oppositional style). Finally, the presence of metacognitive reflection spaces during the online course seems to foster the students' Advanced Epistemic Agency.

Following these findings, one hypothesis is that the three factors favor a change in the "working with knowledge model" that the students espouse (Ferrini \& Cacciamani, 2009). By 
this expression we refer to the students' goal orientations within an online course: knowledge acquisition objectives vs. new Knowledge Building objectives. The knowledge acquisition model assumes that the students perceive their activity as orientated towards acquiring the knowledge transmitted by the teacher, who is the only one responsible for asking questions and evaluating the responses; such a model is highlighted by the students' operating at a level of Epistemic Agency we define as "Basic" in our study. The Knowledge Building model assumes that the students perceive the goal of their activity as directed towards building new knowledge, in a process that sees them actively committed to asking questions and evaluating the produced knowledge and the strategies used to produce it rather than relying on their teacher. This model operationalizes the practice of Epistemic Agency that we define as "Advanced".

From our analyses, it emerges that the quantity of written messages is related to their quality in terms of exploration and evaluation of new contents: those who write more contributions tend to write them also at a higher level of Epistemic Agency. In fact it is possible that the students with central participation, participating in the forum from the beginning of the course with a higher frequency of contributions, may have more opportunities to shift their model from a knowledge acquisition model to a Knowledge Building model). They are more likely than students with peripheral participation to respond to Advanced Epistemic Agency strategies used by the tutor and the other participants. The students with central participation are also more likely to appropriate Advanced Epistemic Agency strategies and then use them throughout the course. As Rogoff, Paradise, Arauz, Correa-Chavez, \& Angelillo (2003) assert intentional participation is a powerful learning tool. Through intentional participation, students learn by observing or listening to (by reading the contributions of) more expert participants in the course activity. 
It is also possible that the students with higher levels participation also benefitted more from tutor requests intended to stimulate an Advanced Epistemic Agency ("define the problems and then show your theory"). A supportive tutor could also facilitate change in the student's working with knowledge model as he or she one intervenes in the course discussion with insightful questions, asks for examples, proposes the students form their own opinions concerning the discussion, offers new cues, and supplies materials upon which to be commented. This style could enable the students to understand on the one hand that asking questions and formulating hypotheses are two important activities in online discussions, and on the other hand to see that they are expected to and justified in expressing their own evaluations of others' ideas. The "oppositional" tutor, in trying to activate a socio-cognitive conflict through objections to the ideas expressed by the participants, may be perceived not as the bearer of a point of view with which one can face himself/herself dialectically, but as an expert expressing an established opinion due to his status of advanced expertise. Thus oppositional tutor's action runs the risk of being perceived as an evaluative action of the ideas expressed by the participants. This perception can drive the students to focus on the model centered on knowledge acquisition just considering evaluation as an action exclusively pertaining to the teacher. Such an interpretation can be supported by studies on the sociocognitive conflict in learning environments (Doise, 1990; Doise \& Mugny, 1984; Mugny \& Doise, 1978). In an elaboration of the Piagetian perspective, Doise and Mugny showed that in a socio-cognitive conflict, the production of different cognitive approaches to the same problem, starting from the social interaction, leads to progress when a student takes into account the incompatibility between his/her perspective and that of another point of view. Status differences between a tutor and a student can hinder such a process. In fact Azmitia (1988) highlights that individuals working in pairs on a learning task, even at an early preschool age, are aware of their own level of expertise in relation to the other. When they 
perceive an unequal power and a different level of expertise in comparison to the task, the pair integration model becomes more similar to the adult-child, or expert-non-expert relationship. It implies a passive acceptance of their own partner's inputs, without any active commitment to a cognitive restructuring work.

The presence of a metacognitive reflection space as well can favor the abovementioned change of model. Metacognitive reflection during the course requires students to state the relevant ideas emerging from the discussion and to state both the strong and the weak points of the strategies used during the work. This activity could then orientate the students towards a deeper exploration of problems and to the formulation of hypothesis. They can also see the similar evaluative operation carried out by their course peers. It thus favors an increase in the evaluative practice of both emerging contents and strategies during the forum. Luca and McMahon (2004), who state expressing the metacognitive processes in a workgroup domain takes place through self- and hetero-evaluation, corroborate our interpretation. Such an evaluative process involves the students expressing judgments on their learning and that of others. It contributes to the development of autonomous individuals, who are responsible and able to reflect on themselves (Sambell, McDowell \& Brown, 1998; Schon, 1987). In addition, the online metacognitive reflection space can enable the students to have a place where they can question themselves about the meaning of the activity, on its objectives and on the Knowledge Building perspective (e.g., "What are we doing? Why?"). We know from existing literature that the development of metacognitive expertise has as its central element reflection and the clear identification of the objective of study (Orsmond, Merry \& Reiling, 1996; Stefani, 1994). Metacognitive evaluation (a component of the Advanced Epistemic Agency) therefore becomes a common practice within the community that offers students the possibility of progressively improving their work strategies. 
We now consider limitations of the present study, given how we defined online participation. As we have seen in literature (Hrastinski, 2008), online participation can assume different units of analysis. In our research, to define the level of participation we take into account the quantities of written notes, only considering the contributions produced as a replies or build-on notes in discussion threads that had already been started. This attempts to define participation in terms of "relationship among the participants" and in maintaining relationships with others. But participation is a complex construct mediated by both physical and psychological tools. Participation is not synonymous with speaking or writing a message, and may be supported by engagement in different types of shared activities (Hrastinski, 2009). In addition we decided to analyze only the contributions by the students who had "extreme" participation, defined either as central or peripheral. This choice enables us to examine the effect of the participation variable and to evaluate the effect of organizational variables (tutorship style and metacognitive reflection) keeping in the sample a heterogeneity of the students' participation level. It would be worth including in the future analysis of contributions of that section of students who are neither "central" nor "peripheral" within the community, taking part in the group debate in a way that can be defined as "intermediate" to obtain a more holistic view of the group's Knowledge Building dynamics.

\section{Conclusion}

The results of this study offer some useful directions for the planning of online courses that may enable students to develop skills for creating new knowledge. Future research directions could first investigate if the levels of Advanced Epistemic Agency change before and after the metacognitive reflection activity and if there are some differences in the metacognitive reflections on the students' strategies between those with an Advanced Epistemic Agency and those with a Basic one. In addition, it would be interesting to identify 
other tutorship styles that are effective in the management of an online course, as well as to focus the attention on the search for a course's organizational elements or didactic strategies that could either promote the development of the skills for building new knowledge in peripheral students, or encourage their level of participation. This would be crucial in supporting quality learning outcomes and retention of students as online courses and programs continue to flourish.

\section{References}

Allen, E. I., \& Seaman, J. (2004). Entering the mainstream: The quality and extent of online education in the United States, 2003 and 2004. Needham, MA.: Sloan Center for Online Learning in Education (SCOLE).

Allen, E. I., \& Seaman, J. (2008). Staying the course: Online education in the United States, 2008. Needham, MA.: Sloan Center for Online Learning in Education (SCOLE).

Azmitia, M. (1988). Peer interaction and problem solving: When are two heads better than one? Child Development, 59, 87-96.

Berge, Z.L. (1997) Characteristics of online teaching in post-secondary, formal education. Educational Technology, 37(3), 35-47.

Berge, Z., \& Collins, M. (1996). Facilitating interaction in computer mediated online courses. FSU/AECT Distance Education Conference, Tallahasee FL. Retrieved Dec. 2010 from: http://www.emoderators.com/moderators/flcc.html

Bonaiuti, G. (Ed.) (2006) E-learnig 2.0. Il futuro dell'apprendimento in rete tra formale ed informale. Trento: Erickson.

Booker, Q.E., \& Rebman, C.M., Jr. (2005). E-student retention: factors affecting customer loyalty for online program success. Issues in Information Systems, 6(1), 183-189. 
Brown, A. L., \& Campione, J. C. (1994). Guided discovery in a community of learners. In K. McGilly (Ed.), Classroom lessons: Integrating cognitive theory and classroom practice (pp. 229-270). Cambridge, MA: Bradford Books/MIT Press.

Cacciamani, S. (2001). Costruire conoscenza, attraverso le nuove tecnologie: Knowledge Forum e i possibili scenari formativi. Orientamenti Pedagogici,1, 84-97.

Cacciamani, S., \& Ferrini, T. (2007). Costruire conoscenza in un corso universitario on line è davvero possibile? Tecnologie didattiche, 40, 28-35.

Calvani, A., \& Rotta, M. (2000). Fare formazione in internet. Manuale di didattica online. Trento: Erickson.

Campbell, J.P., De Blois, P.B., \& Oblinger, D.G. (2007). Academic analytics: a new tool for a new era. EDUCAUSE Review, 42(4), 42-57.

Cesareni, D., Ligorio, M. B., \& Pontecorvo, C. (2001). Discussione e argomentazione in un forum universitario. TD Tecnologie didattiche, 24, 55-65.

Cesareni, D., \& Martini, F. (2005) Costruire conoscenza in un forum universitario. Rassegna di Psicologia, 22, 89-112.

Cesareni, D., Albanese, O., Cacciamani, S., Castelli, S., De Marco, B., Fiorilli, C., Luciani M., Mancini I., Martini F., \& Vanin L. (2008) Tutorship styles and knowledge building in an online community: Cognitive and metacognitive aspects. In B. M. Varisco (Ed.), Psychological, pedagogical and sociological models for learning and assessment in virtual communities (pp.13-56). Milano: Polimetrica International Scientific Publisher.

Chan, C., Burtis, J., \& Bereiter, C. (1997). Knowledge building as a mediator of conflict in conceptual change. Cognition and Instruction, 15, 1-40. 
Choi, I., Land, S.M., \& Turgeon, A.J. (2005). Scaffolding peer-questioning strategies to facilitate metacognition during on line small group discussion. Instructional Science, $33,483-511$.

Doise, W. (1990). The development of individual competencies through social interaction. In H. C. Foot, M. J. Morgan, \& R. H. Shute (Eds.), Children helping children (pp. 4364). New York, NY: John Wiley and Sons.

Doise, W., \& Mugny, G. (1984). The social development of the intellect. Oxford: Pergamon Press.

Dziuban, C., Shea, P., \& Arbaugh, J. (2005). Faculty roles and satisfaction in ALNs. In S. R. Hiltz \& R. Goldman (Eds.) Learning together online: Research on asynchronous learning networks (pp. 169-190). Mahwah, NJ: Lawrence Erlbaum Associates.

Edwards, M.A., \& Fintan, C. (2001). Supporting the collaborative learning of practical skills with computer-mediated communications technology. Educational Technology \& Society, 4(1), 80-92.

Ferrini T., \& Cacciamani, S. (2009). Costruzione di conoscenza e livelli di partecipazione in un corso on line. In S. Cacciamani (Ed.), Knowledge Building Communities Ripensare la Scuola e l'Università come comunità di ricerca (pp.95-110). Napoli: Scriptaweb.

Garrison, D.R., \& Cleveland-Innes, M. (2005). Facilitating cognitive presence in online learning: Interaction is not enough. The American Journal of Distance education, 19(3), 133-148.

Hakkarainen, K. \& Sintonen, M. (2002). Interrogative model of inquiry and computersupported collaborative learning. Science \& Education, 11, 25-43.

Hrastinski, S. (2008). What is online learner participation? A literature review. Computers \& Education, 51, 1755-1765. 
Hrastinski, S (2009). A theory of online learning as online participation. Computers \& Education, 52, 78-82.

Hwang, A., \& Arbaught, J. B. (2009). Seeking feedback in blended learning: Competitive versus cooperative student attitudes and their links to learning outcome. Journal of Computer Assisted Learning, 25, 280-293.

Kim, J., \& Gil, Y. (2007). Incorporating tutoring principles into interactive knowledge acquisition. International Journal of Human-Computer Studies, 65(10), 852-872.

Koh, J., Kim, Y.-G., Butler, B., \& Bock, G.W. (2007) Encouraging participation in virtual communities. Communication of the ACM, 50(2), 68-73. Retrieved December 1, 2010 from http://portal.acm.org/citation.cfm?id=1216016.1216023 .

LaGrange, A., \& Foulkes, E. (2004). Emergent framework for ICT integration within faculties of education in Canada. Ottawa: Report prepared for Industry Canada on behalf of Canadian Association of Deans of Education.

Lakkala, M., Rahikainen, M., \& Hakkarainen, K. (2001). Perspective of CSCL in Europe: A review. Report D1 of European Project ITCOLE. Contract IST-2000-26249.

Lave, J., \& Wenger, E. (1991). Situated learning: Legitimate peripheral participation. New York: Cambridge University Press.

Lewis, L., Levin, D., \& Green, B. (1999). Distance education at postsecondary institutions: 1997-98. National Center for Education Statistics, U.S. Department of Education.

Luciani, M. (2007) Il ruolo del tutor nell'interazione on line. In S.Cacciamani, M. Luciani e Gruppo KF (Eds.), Una Knowledge Building Community nella formazione universitaria on line, (pp.66-91). Brescia: Polimetrica.

Luca, J. \& McMahon, M. (2004). Promoting metacognition through negotiated assessment. In R. Atkinson, C. McBeath, D. Jonas-Dwyer \& R. Phillips (Eds), Beyond the comfort zone: Proceedings of the 21st ASCILITE Conference (pp. 562-570). Perth, 5-8 
December. Retrieved December 2010 from:

http://www.ascilite.org.au/conferences/perth04/procs/luca.html

Martinez, M. (2003). High attrition rates in e-learning: challenges, predictors and solutions.

The e-learning developers journal, 13, 1-9.

Mayer, R.E. (2003). The promise of multimedia learning: using the same instructional design methods across different media. Learning and Instruction, 13, 125-139.

Mazzoni, E. (2005). La Social Network Analysis a supporto delle interazioni nelle comunità virtuali per la costruzione di conoscenza. TD, Tecnologie Didattiche, 35(2), 54-63

Moshinskie, J. (2002). How to keep e-Learners from e-scaping. In A. Rossett (Ed.), The ASTD E-Learning Handbook (pp. 218-233). New York (NY): McGraw-Hill.

Mugny, G., \& Doise, W. (1978). Socio-cognitive conflict and structure of individual and collective performances. European Journal of Social Psychology, 8, 181-192.

Muukkonen H., Hakkarainen, K., \& Lakkala, M. (1999). Collaborative technology for facilitating Progressive Inquiry: The future Learning Environment tools. In C. Hoadley \& Roschelle (eds.), Proceedings of the CSCL '99: The Third International Conference on Computer Supported Collaborative Learning, (pp. 406-415). Mahwah (NJ): Erlbaum.

Narciss, S., Proske, A., \& Koerndle, H. (2007). Promoting self-regulated learning in webbased learning environments. Computers in Human Behavior, 23(3), 1126-1144.

Orsmond, P., Merry, S., \& Reiling, K. (1996). The importance of marking criteria in the use of peer assessment. Assessment and Evaluation in Higher Education, 21(3), 239-250.

Palincsar, A.S., \& Brown, A.L. (1984). Reciprocal teaching of comprehension fostering and monitoring activities. Cognition and Instruction, 1, 117-175.

Pellerey, M. (2003). Processi autoregolativi e attribuzioni causali. Orientamenti Pedagogici, 50(4), 651-677. 
Rogoff, B., Paradise, R., Arauz, R. M., Correa-Chavez, M., \& Angelillo, C. (2003). Firsthand learning through intent participation. Annual Review of Psychology, 54, 175-203.

Rotta, M. (2002). Il tutor on line: tipologie. Retrieved November 2005 from: http://formare.erickson.it/archivio/febbraio/tipologie.html

Sambell, K., McDowell, L., \& Brown, S. (1998). But is it fair? An exploratory study of student perceptions of the consequential validity of assessment. Studies in Educational Evaluation, 23, 349-371.

Sánchez-Alonso, S., \& Vovides, Y. (2007). Integration of metacognitive skills in the design of learning objects. Computers in Human Behaviour, 23(6), 2585-2595.

Scardamalia, M. (2002). Collective cognitive responsibility for the advancement of knowledge. In B. Smith (Ed.), Liberal education in a knowledge society (pp.76-98). Chicago, IL: Open Court.

Scardamalia, M., Bereiter, C., McLean, R. S., Swallow, J., \& Woodruff, E. (1989). Computer supported intentional learning environments. Journal of Educational Computing Research, 5, 51-68.

Scardamalia, M., \& Bereiter, C. (1992). An architecture for collaborative Knowledge Building. In E. De Corte et al. (Ed.) Computer Based Learning Environments (pp. 4467). Berlin: Springer Verlag.

Scardamalia, M., \& Bereiter, C. (1994). Computer support for knowledge-building communities. The Journal of the Learning Sciences, 3, 265-283.

Scardamalia, M., \& Bereiter, C. (2006). Knowledge building: Theory, pedagogy and technology. In K. Sawyer (Ed.), Cambridge handbook of the learning sciences (pp.97115). Cambridge: Cambridge University Press.

Schon, D. A. (1987). Educating the reflective practitioner: Towards a new design for teaching and learning in the professions. San Francisco: Jossey Bass. 
Shea, P., Pickett, A., \& Sau Li, C. (2005). Increasing access to Higher Education: A study of the diffusion of online teaching among 913 college faculty. The International Review of Research in Open and Distance Learning, 6 (2), Retrieved from http://eric.ed.gov/PDFS/EJ846839.pdf

Siemens, G. (2010, Aug 25). What are Learning Analytics? Retrieved from http://www.elearnspace.org/blog/2010/08/25/what-are-learning-analytics/

Stefani, L. A. J. (1994). Peer, self, and tutor assessment: Relative reliabilities. Studies in Higher Education, 19 (1), 69-75.

Tallent-Runnels, M., Thomas, J., Lan, W., Cooper, S., Ahern, T., Shaw, S., \& Liu, X. (2006). Teaching courses online: A review of the research. Review of Educational Research, $76(1), 93-135$.

Wenger, E. (1998). Communities of practice: Learning, meaning and identity. New York: Cambridge University Press.

Wise, K., Hamman, B., \& Thorson, K. (2006). Moderation, Response Rate, and Message Interactivity: Features of Online Communities and Their Effects on Intent to Participate. Journal of Computer-Mediated Communication, 12(1), 24-41.

Zhu, E. (2007). Interaction and cognitive engagement: An analysis of four asynchronous online discussions. Instructional Science: An International Journal of Learning and Cognition, 34(6), 451-480.

Zimmerman, B.J. (2000). Attaining self-regulation: A social cognitive perspective. In M. Boekaerts, P.R. Pintrich, \& M. Zeidner (Eds.), Handbook of self-regulation (pp.1339). San Diego, (CA): Academic Press.

Zimmerman, B.J. (2002). Efficacité perçue et autorégulation des apprentissage durant les etudes: une vision cyclique”. In P. Carré, A. Moisan (Eds.), La formation autodirigée. Aspects psychologiques et pédagogiques (pp. 69-88). Paris (FR): L'Harmattan. 
Table 1 Research plan: participation level variable, number of students

\begin{tabular}{lcc}
\hline & \multicolumn{3}{c}{ Participation level } \\
\hline & Central & Peripheral \\
\cline { 2 - 4 } & 36 & 31 \\
Number of students & & \\
\hline (Aosta and Rome) & & \\
\hline
\end{tabular}

Table 2 Research plan: tutorship style variable, number of students

\begin{tabular}{lcc}
\hline & \multicolumn{2}{c}{ Tutorship style } \\
\hline & Oppositional & Supportive \\
\cline { 2 - 3 } & 18 (2 groups) & 13 (2 groups $)$ \\
Number of students & & \\
\hline
\end{tabular}

Table 3 Research plan: metacognitive reflection variable, number of students

\begin{tabular}{lcc}
\hline & \multicolumn{2}{c}{ Metacognitive reflection } \\
\hline & Yes & No \\
\cline { 2 - 3 } $\begin{array}{c}\text { Number of students } \\
\text { (Aosta and Rome })\end{array}$ & 21 (2 groups) & 15 (1 group $)$ \\
\hline
\end{tabular}


Table 4

Coding scheme for the content analysis.

\begin{tabular}{|c|c|c|}
\hline $\begin{array}{l}\text { Epistemic } \\
\text { Agency }\end{array}$ & $\begin{array}{l}\text { Second-Level } \\
\text { Categories (Activities) }\end{array}$ & First-Level Categories (Contents) \\
\hline Advanced & $\begin{array}{l}\mathrm{V}=\text { Evaluating contents } \\
\text { and strategies }\end{array}$ & $\begin{array}{l}\text { C1 Research questions or problems: questions regarding the contents of the course, presence of question } \\
\text { marks or interrogative expressions. E.g.: I wonder how the attachment bond develops } \\
\text { C2 Hypotheses concerning contents: proposed explanations of questions discussed E.g.: This fact could be explained by ... } \\
\text { C3 Comments (evaluations of contents): expressions of agreement or disagreement, positive or negative judgments } \\
\text { on an idea expressed by another participant } \\
\text { E.g.: According to me what you have said is very useful ... } \\
\text { N.B. this category does not include global judgments. E.g.: It seems to me that the level of debate and the capacity for } \\
\text { analysis are considerable. } \\
\text { C4 Metacognitive reflections: evaluations or comments about study strategies used during the online course. } \\
\text { Explicit reference is made to cognitive activity. } \\
\text { E.g.: I want to concentrate on... This post has made me reflect. } \\
\text { These also include metacommunications. E.g.: I shall now briefly reflect on my work as an educator. }\end{array}$ \\
\hline Basic & 12 = Elaborating information & $\begin{array}{l}\text { C5 Practical examples: examples drawn from the participant's experience } \\
\text { E.g.: It's happened to me that ... } \\
\text { C6 Information obtained from reliable sources, and data relative to experimentation: theoretical information } \\
\text { whose source is explicitly cited. E.g.: I've read in the book that... } \\
\text { Also belonging to this category is information drawn from sources containing research data. } \\
\text { E.g.: As Cole shows in his study... } \\
\text { C7 Repetitions of ideas expressed by other members of the community: explicit statement that reference is } \\
\text { being made to someone else's idea. E.g.: It reminds me of your message in the previous module about the language } \\
\text { developed to achieve distant goals (freedom)... } \\
\text { C8 Syntheses of the ideas of several participants: assemblies of several ideas (e.g. indented or bulleted lists). } \\
\text { E.g.: Experience has shown: } \\
\text { - that MDUs can be characterized differently in different contexts ("he's a child spoiled by his family" is typical of the school); } \\
\text { - the effects that they have on people in such contexts; } \\
\text { - the ways and means to change them. }\end{array}$ \\
\hline
\end{tabular}

Table 5 Number of participants, number of inserted comments and segments, average comments and segments per student

\begin{tabular}{ccccc}
\hline $\begin{array}{c}\text { Number of } \\
\text { students }\end{array}$ & $\begin{array}{c}\text { Number of } \\
\text { comments }\end{array}$ & $\begin{array}{c}\text { Average } \\
\text { comments/students }\end{array}$ & $\begin{array}{c}\text { Number } \\
\text { of } \\
\text { segments }\end{array}$ & $\begin{array}{c}\text { Average } \\
\text { segment/comment }\end{array}$ \\
\hline 67 & 977 & 14.16 & 5437 & 5.56 \\
\hline
\end{tabular}

Table 6 Basic and Advanced Epistemic Agency among students with central and peripheral participation in Rome and Aosta

\begin{tabular}{lcc}
\hline & $\begin{array}{c}\text { Basic Epistemic } \\
\text { Agency }\end{array}$ & $\begin{array}{c}\text { Advanced Epistemic } \\
\text { Agency }\end{array}$ \\
\hline $\begin{array}{l}\text { Peripheral participation } \\
(N=31)\end{array}$ & 531 & 585 \\
& $47.58 \%$ & $52.42 \%$ \\
$\begin{array}{l}\text { Central participation } \\
(N=36)\end{array}$ & 1740 & \\
\hline
\end{tabular}




\section{Figure(s)}

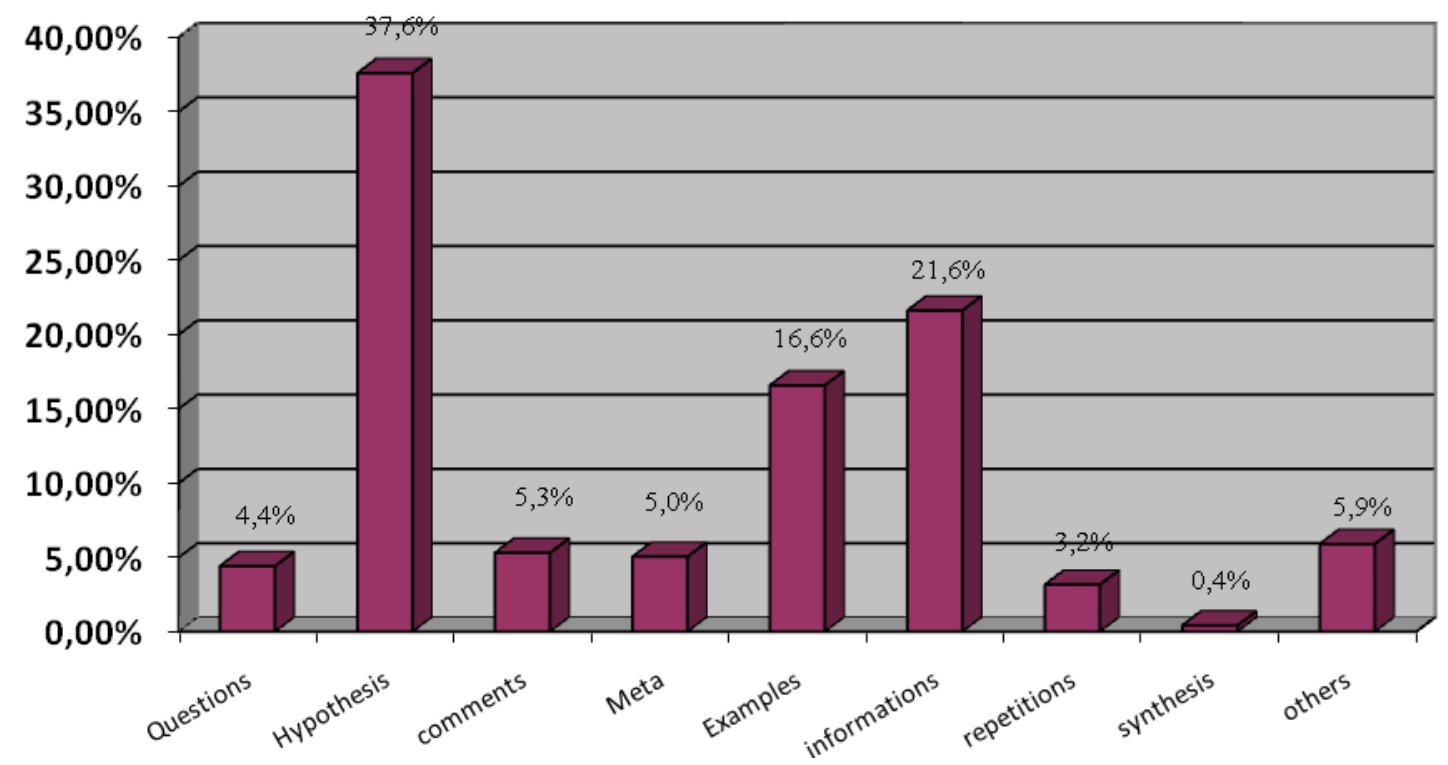

Figure 1 Contents of the segments

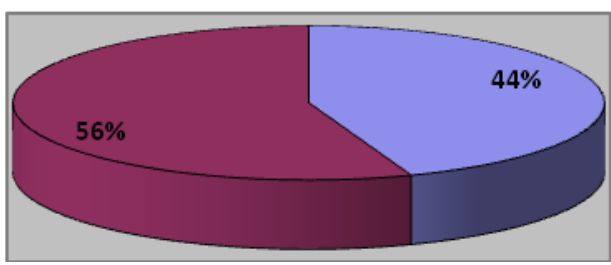

$$
\begin{aligned}
& \text { DBasic Epistemic } \\
& \text { Agency } \\
& \text { Advanced Epistemic } \\
& \text { Agency }
\end{aligned}
$$

Figure 2 Basic and Advanced Epistemic Agency 


\section{*Hig hlig hts}

Highlights:

- Higher level of participation is associated with a higher level of epistemic agency.

- A supportive tutorship style foster a higher level of epistemic agency.

- Ample opportunities for metacognitive reflection on the students' own participation strategies help a higher level of epistemic agency 